Research Article

\title{
New Nonlinear Cumulative Fatigue Damage Model Based on Ecological Quality Dissipation of Materials
}

\author{
Hongsong Li $(\mathbb{D}$, Yongbao Liu, Xing He $\mathbb{D}$, and Wangtian Yin \\ College of Power Engineering, Naval University of Engineering, Wuhan 430033, China \\ Correspondence should be addressed to Xing He; hexing_mail@163.com
}

Received 13 January 2021; Revised 23 February 2021; Accepted 27 March 2021; Published 10 April 2021

Academic Editor: Antonio Concilio

Copyright (C) 2021 Hongsong Li et al. This is an open access article distributed under the Creative Commons Attribution License, which permits unrestricted use, distribution, and reproduction in any medium, provided the original work is properly cited.

\begin{abstract}
The failure of many aircraft structures and materials is caused by the accumulation of fatigue damage under variable-amplitude cyclic loading wherein the damage evolution of materials is complicated. Therefore, to study the cumulative fatigue damage of materials under variable-amplitude cyclic loading, a new nonlinear fatigue damage accumulation model is proposed based on the ecological quality dissipation of materials by considering the effects of load interaction and sequence. The proposed new model is validated by the test data obtained for three kinds of material under multilevel fatigue loading. Compared with the Miner model and Kwofie model, the proposed model can more effectively analyse the accumulative damage and predict fatigue life of different materials under variable-amplitude cyclic loading than others. The study provides a basis for predicting fatigue life accurately and determining reasonable maintenance periods of aircraft structures.
\end{abstract}

\section{Introduction}

Fatigue damage is one of the major failure modes of engineering structures and materials [1]. A reliable accumulative damage model is very important for assessing the integrity and safety of aircraft structures and materials [2], many of which are actually subjected to variable-amplitude cyclic loading. The damage evolution behaviours of materials under variable-amplitude cyclic loading are complicated. Therefore, studying the cumulative fatigue damage of materials under variable-amplitude cyclic loading is of great significance to analyse the fatigue life and determine reasonable maintenance periods.

The fatigue damage accumulation theory can be summarized into the linear damage accumulation theory (Miner model for short) and the nonlinear damage cumulative theory [3]. The Miner model is simple and easy to use [4], but it does not take the influences of load interaction and sequence into account. Numerous experimental studies have shown that both load sequence and interaction greatly influence the fatigue lives of materials [5-7]. Therefore, sometimes the lives predicted by the Miner model are quite different from experimentally obtained ones. To solve this problem, several nonlinear fatigue damage accumulation models have been proposed of which the most typical is the Carten-Dolan model (expressed as $D=\sum_{i}\left(n_{i} / N_{\mathrm{f} \max }\right)$ $\left.\left(\sigma_{i} / \sigma_{\max }\right)^{d}\right)$ [8]. The material parameter $d$ in the CartenDolan model is not only related to material type but also related to specimen shape, loading stress level, and load spectrum, so it is difficult to determine the parameter $d$. To reflect the nonlinear effects of load interaction, Liu et al. [9] modified $d$ by introducing a power function of the stress ratio between two load levels and proposed an improved CartenDolan model. Chaboche and Lesne [10] proposed a nonlinear damage accumulation model based on continuous damage mechanics. On the basis of the Chaboche model, Dattoma et al. [11] considered the influence of the load sequence and derived a damage accumulation model for materials under multilevel cyclic loading. Gao et al. [12] modified the Chaboche model to predict the fatigue life of compressor blades under multiaxial loads and combined high and low cycle loads. Although the Chaboche model considers the influences of the average stress and load sequence and can accurately describe the cumulative damage, numerous material parameters must be determined. Based on the $S-N$ curve, Kwofie and Rahbar [13] established a nonlinear fatigue damage accumulation model by introducing the 
concept of fatigue driving stress. In damage accumulation, the physical properties of materials gradually degrade with the increasing number of load cycles. However, the above model cannot explain the mechanism by which material properties degrade with accumulating fatigue damage. Based on the toughness-exhaustion model, Peng et al. [14] introduced load interaction factors and independently proposed improved fatigue damage accumulation models. On the basis of conducting a comparative study on five nonlinear fatigue damage accumulation models, Zhu et al. [15] presented a new nonlinear fatigue damage accumulation model by considering the effects of load interaction and sequence. Xia et al. [16] proposed a fatigue damage accumulation model considering the exhaustion of static toughness based on isodamage curves. Böhm et al. [17] proposed a material memory-based fatigue damage accumulation model analogy with the Ebbinghaus forgetting curve [18]. Peng et al. [19] proposed a phenomenological fatigue damage accumulation model by combining the material memory concept and the remaining $S-N$ curve, but the model did not take into account the effects of the average stress and load interaction on materials. On the basis of the model proposed by Peng et al., Zhou et al. [20] proposed a new material memory degradationbased damage model by introducing a load interaction factor and using the Smith-Watson-Topper (SWT) average stress correction criterion [21]. The SWT criterion did not consider the influence of the material type on the average stress correction. Therefore, the corrections for some materials were nonspecific [22]. The Ebbinghaus forgetting curve indicates that the forgetting velocity is first fast and then slow, which is inconsistent with the observation that material physical properties degrade first slow and then fast $[23,24]$ during fatigue damage accumulation.

We drew an analogy with litter decomposition in an ecosystem during which some organic matter decomposes first slowly and then quickly and regarded the degradation of material performances as the ecological quality dissipation of materials. On this basis, a nonlinear fatigue damage accumulation model was developed by considering the influences of material type, load interaction, and load sequence. Through the validation of test data, the proposed model can be used to study fatigue damage accumulation and predict the fatigue life effectively and accurately.

\section{Formulation of the Nonlinear Fatigue Damage Accumulation Model}

During fatigue damage accumulation, the physical properties of materials continue to degrade with the increasing number of load cycles. Just as litter in an ecosystem decomposes over time, material physical properties analogously degrade as the ecological quality dissipation of the materials.

The decomposition of litter in an ecosystem is usually expressed as an exponential function of time, and a widely used expression [25] is

$$
\frac{d X}{X}=-k d t
$$

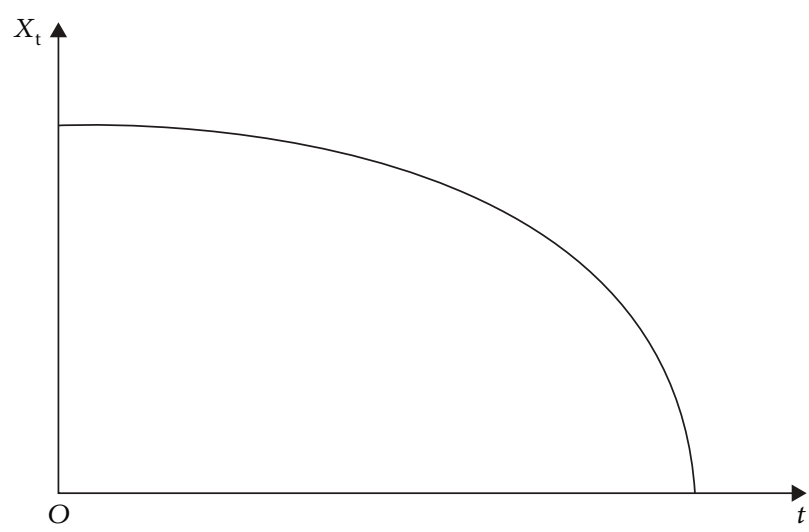

FIgURE 1: Curve representing decomposition of organic matter in litter.

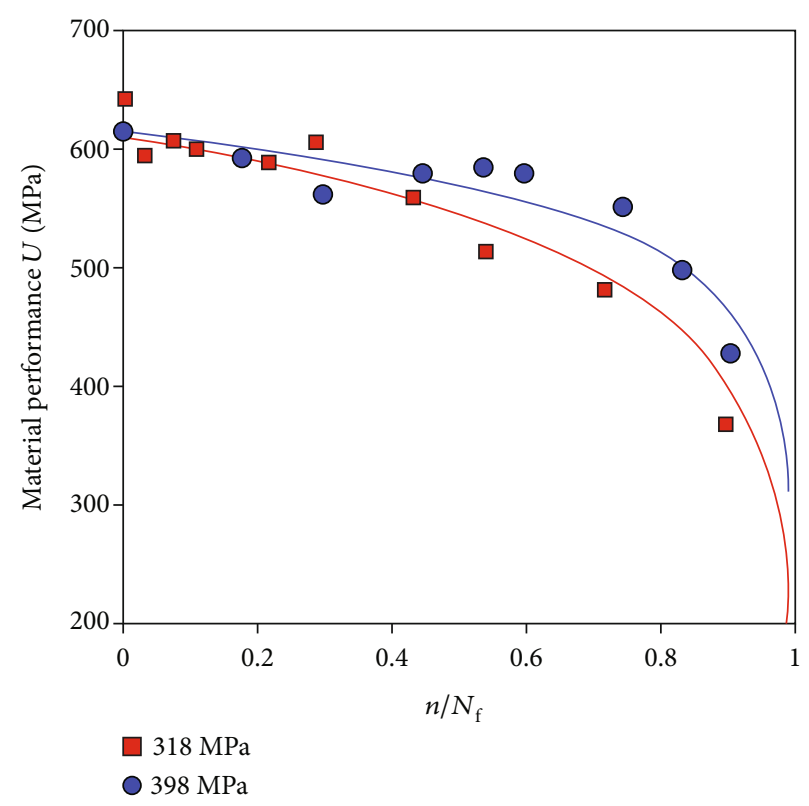

FIGURE 2: Curve representing degradation of material performance.

where $X$ is the amount of litter at a given moment, $t$ is the time, and $k$ is the instantaneous decomposition rate.

P. Rovira and R. Rovira [26] replaced $k$ in Equation (1) with a function of time $(f(t))$ and then integrated the resulting equation to obtain a more general expression describing the decomposition of litter.

$$
X_{\mathrm{t}}=X_{0} e^{-\int_{0}^{t} f(t) d t},
$$

where $X_{\mathrm{t}}$ is the amount of litter at time $t$ and $X_{0}$ is the initial amount of litter.

If the decomposition rate $(f(t))$ follows an exponential law and assuming $f(t)=e^{-t}$, we can obtain

$$
X_{\mathrm{t}}=X_{0} e^{\left(e^{-t}-1\right)} .
$$

Because the double-exponential function changes faster than the single-exponential one for the same base, another 


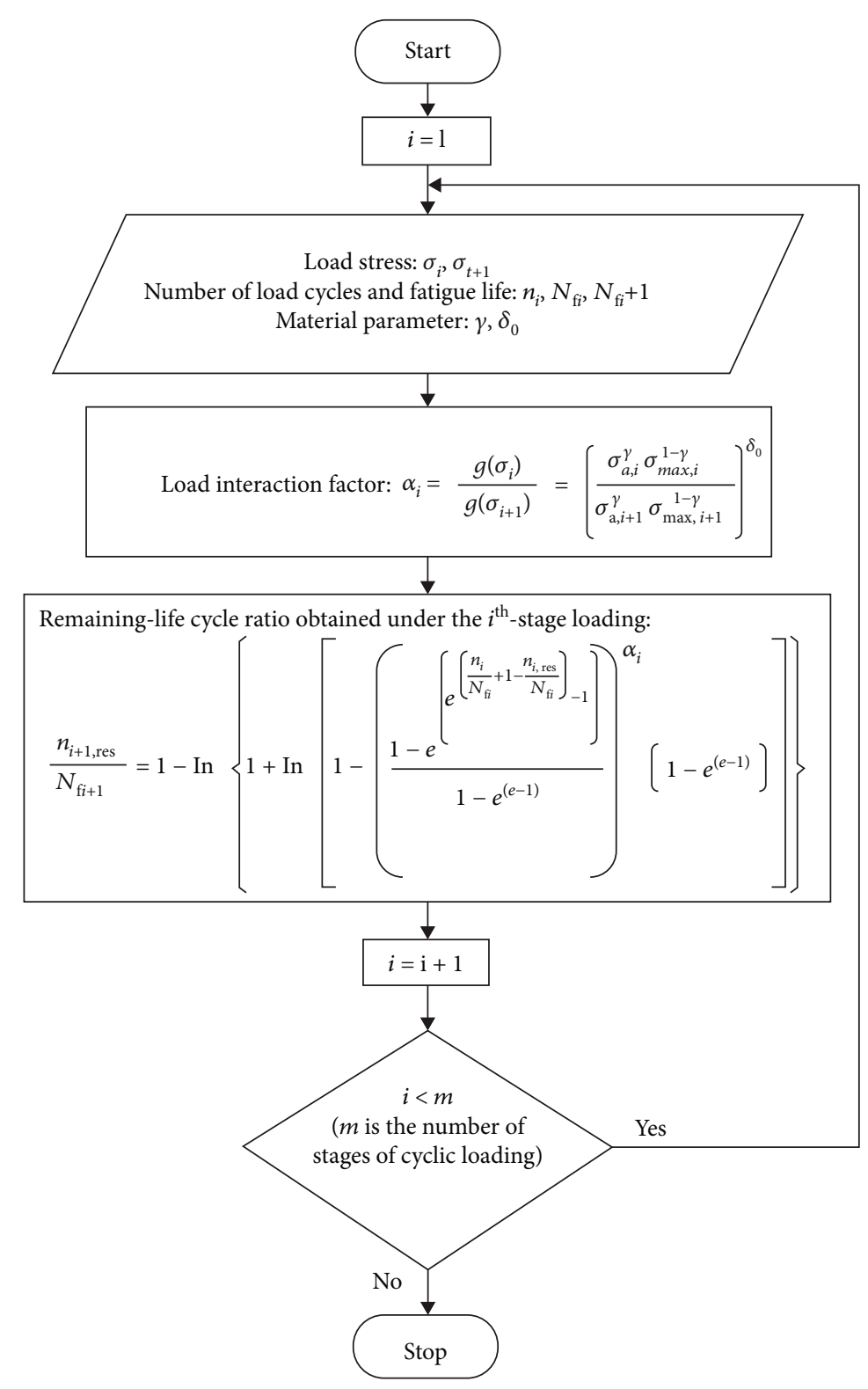

Figure 3: Flowchart of life prediction using the proposed model.

expression can be obtained indicating that the organic matter in the litter decomposes first slow and then fast.

$$
X_{\mathrm{t}}=A-B e^{\left(e^{t}-1\right)}
$$

where $A$ and $B$ are correlation parameters. The curve represented by Equation (4) is depicted in Figure 1.

According to the test data in Reference [23], the curve of degradation of material performance with the increase in the number of load cycles is depicted in Figure 2.

By comparing the curve represented by Equation (4) with the curve obtained based on test data in Figure 2, it is found that the degradation process of material performance has many similarities with the decomposition process of litters in the ecosystem. The variable $t$ in Equation (4) is replaced by the normalized number of load cycles $n / N_{f}$, and the eco- logical quality function of materials is obtained:

$$
X(n)=A-B e^{\left(e^{n / N_{f}}-1\right)},
$$

where $n$ is the number of load cycles and $N_{\mathrm{f}}$ is the fatigue life.

The ecological quality of materials dissipates gradually under the cyclic loading. The dissipation degree of ecological quality of materials is expressed as

$$
\Delta X(n)=\frac{X(0)-X(n)}{X(0)-X\left(N_{\mathrm{f}}\right)}=\frac{1-e^{\left(e^{n / N_{f}}-1\right)}}{1-e^{(e-1)}} .
$$

When $n$ is 0 in the initial state, the dissipation degree of ecological quality of materials $\Delta X(0)$ is 0 . When $n$ is $N_{\mathrm{f}}$ in the failure state, the dissipation degree of ecological quality of materials $\Delta X\left(N_{\mathrm{f}}\right)$ is 1 . 


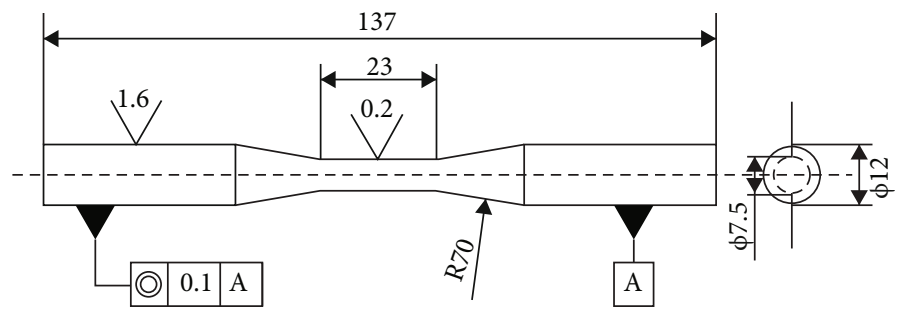

Figure 4: Geometry of 30NiCrMoV12 alloy steel specimens (dimensions in mm).

TABLE 1: Experimentally obtained and corresponding theoretical remaining life values predicted by the Miner, Kwofie, and proposed new model for the $30 \mathrm{NiCrMoV} 12$ alloy steel under two-level cyclic loading.

\begin{tabular}{|c|c|c|c|c|c|c|}
\hline \multirow{2}{*}{$\frac{\text { Load sequence }}{\sigma_{\max }(\mathrm{MPa})}$} & \multicolumn{3}{|c|}{ Test data } & \multirow{2}{*}{$\frac{\text { Miner model }}{n_{2 \mathrm{p}}(\text { cycle })}$} & \multirow{2}{*}{$\frac{\text { Kwofie model }}{n_{2 p} \text { (cycle) }}$} & \multirow{2}{*}{$\frac{\text { New model }}{n_{2 p} \text { (cycle) }}$} \\
\hline & $n_{1}($ cycle $)$ & $n_{1} / N_{\mathrm{f} 1}$ & $n_{2}$ (cycle) & & & \\
\hline & 13749 & 0.25 & 51304 & 109313 & 100352 & 39438 \\
\hline \multirow[t]{3}{*}{$485-400(\mathrm{H}-\mathrm{L})$} & 27499 & 0.50 & 45765 & 72875 & 66901 & 23908 \\
\hline & 41249 & 0.75 & 16032 & 36438 & 33451 & 11729 \\
\hline & 17013 & 0.25 & 66845 & 85407 & 81630 & 51946 \\
\hline \multirow[t]{3}{*}{$465-420(\mathrm{H}-\mathrm{L})$} & 34072 & 0.50 & 30405 & 56938 & 54427 & 31898 \\
\hline & 51040 & 0.75 & 38262 & 28469 & 27210 & 15629 \\
\hline & 20082 & 0.25 & 79372 & 85407 & 82847 & 61988 \\
\hline \multirow[t]{3}{*}{$450-420(\mathrm{H}-\mathrm{L})$} & 40165 & 0.50 & 24711 & 56938 & 55231 & 38613 \\
\hline & 60248 & 0.75 & 15943 & 28469 & 27616 & 18960 \\
\hline & 36437 & 0.25 & 53348 & 41250 & 44932 & 54918 \\
\hline \multirow[t]{3}{*}{$400-485(\mathrm{~L}-\mathrm{H})$} & 72875 & 0.50 & 45373 & 27500 & 29954 & 53202 \\
\hline & 109312 & 0.75 & 46693 & 13750 & 14978 & 39044 \\
\hline & 36440 & 0.25 & 58594 & 51040 & 54533 & 65445 \\
\hline \multirow[t]{3}{*}{$420-465(\mathrm{~L}-\mathrm{H})$} & 72870 & 0.50 & 56416 & 34027 & 36356 & 54293 \\
\hline & 109310 & 0.75 & 48998 & 17013 & 18177 & 30599 \\
\hline & 28469 & 0.25 & 70530 & 60248 & 62109 & 73665 \\
\hline \multirow[t]{2}{*}{$420-450(\mathrm{~L}-\mathrm{H})$} & 56938 & 0.50 & 39362 & 40165 & 41406 & 56413 \\
\hline & 85407 & 0.75 & 10523 & 20083 & 20703 & 30010 \\
\hline
\end{tabular}

The fatigue damage [27] considering load interaction and load sequence is defined as

$$
D=\left(\frac{n}{N_{\mathrm{f}}}\right)^{g(\sigma)},
$$

where $g(\sigma)$ is a function of cyclic load and is specifically expressed as

$$
g(\sigma)=\zeta_{0}\left(\sigma_{\mathrm{eq}}\right)^{\delta_{0}}
$$

where $\sigma_{\mathrm{eq}}$ is the equivalent stress amplitude when the average stress is equal to 0 and $\zeta_{0}$ and $\delta_{0}$ are material parameters. $\zeta_{0}$ is cancelled out under multilevel cyclic loading. In Reference [27], according to test data of the $30 \mathrm{NiCrMoV} 12$ alloy steel under two-level cyclic loading, the value of $\delta_{0}$ is obtained as -5.78. Through the test data of other materials, it is verified that the value of $\delta_{0}$ as -5.78 is also applicable to the other materials.
Considering the influence of the material type on the average stress correction and the Walker average stress correction criterion $[28,29]$, Equation (8) changes as

$$
g(\sigma)=\zeta_{0}\left(\sigma_{\text {eq }}\right)^{\delta_{0}}=\zeta_{0}\left(\sigma_{\mathrm{a}}^{\gamma} \sigma_{\max }^{1-\gamma}\right)^{\delta_{0}}
$$

where $\sigma_{\mathrm{a}}$ and $\sigma_{\max }$ are the stress amplitude and maximum stress of the cyclic load, respectively, and $\gamma$ is the material parameter. In Reference [30], according to the fatigue performance test data of different materials under different conditions, $\gamma$ can be determined by the following equation:

$$
\gamma=0.5+\frac{\sigma_{\mathrm{u}}-\sigma_{\mathrm{y}}}{\sigma_{\mathrm{u}}+\sigma_{\mathrm{y}}},
$$

where $\sigma_{\mathrm{u}}$ is the ultimate strength and $\sigma_{\mathrm{y}}$ is the yield strength. 


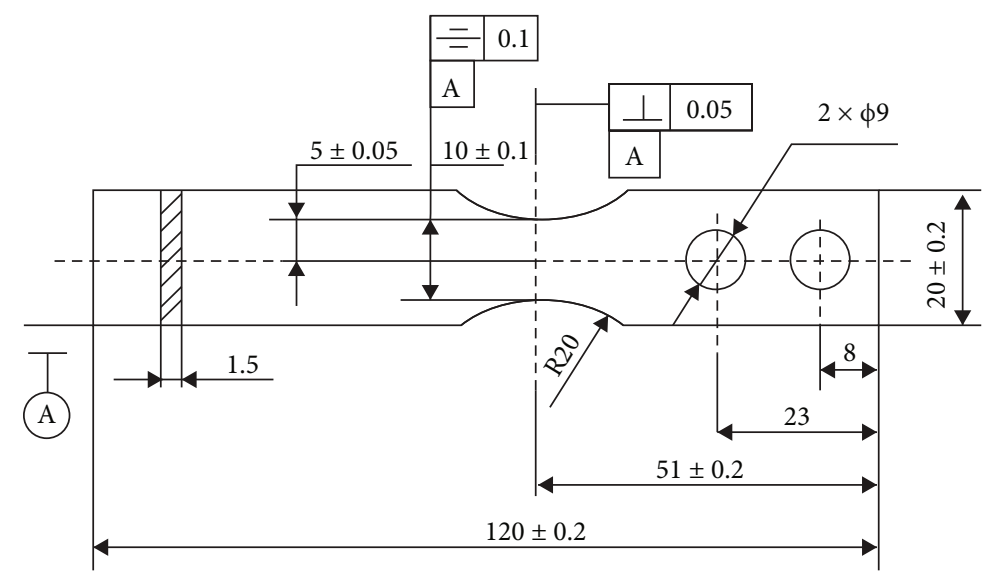

FIGURE 5: Geometry of Ti-6Al-4V titanium alloy specimens (dimensions in $\mathrm{mm}$ ).

TABLE 2: Experimentally obtained and corresponding theoretical remaining life values predicted by the Miner, Kwofie, and proposed new model for the Ti-6Al-4V titanium alloy under two-level cyclic loading.

\begin{tabular}{|c|c|c|c|c|c|c|}
\hline $\begin{array}{l}\text { Load sequence } \\
\sigma_{\max }(\mathrm{MPa})\end{array}$ & $n_{1}$ (cycle) & $\begin{array}{c}\text { Test data } \\
n_{1} / N_{\mathrm{f} 1}\end{array}$ & $n_{2}$ (cycle) & $\begin{array}{c}\text { Miner model } \\
n_{2 \mathrm{p}}(\text { cycle })\end{array}$ & $\begin{array}{c}\text { Kwofie model } \\
n_{2 \mathrm{p}} \text { (cycle) }\end{array}$ & $\begin{array}{c}\text { New model } \\
n_{2 \mathrm{p}} \text { (cycle) }\end{array}$ \\
\hline \multirow{5}{*}{$647-517(\mathrm{H}-\mathrm{L})$} & 10000 & 0.27 & 43000 & 104852 & 92924 & 31012 \\
\hline & 12000 & 0.32 & 77900 & 97670 & 86559 & 28123 \\
\hline & 18000 & 0.48 & 35700 & 74689 & 66192 & 20418 \\
\hline & 20000 & 0.54 & 25500 & 66071 & 58555 & 17878 \\
\hline & 36000 & 0.97 & 5400 & 4308 & 3818 & 1174 \\
\hline \multirow{6}{*}{ 595-517 (H-L) } & 20000 & 0.31 & 27400 & 99106 & 92421 & 46879 \\
\hline & 20000 & 0.31 & 49400 & 99106 & 92421 & 46879 \\
\hline & 30000 & 0.47 & 26900 & 76125 & 70990 & 34170 \\
\hline & 40000 & 0.62 & 22300 & 54580 & 50898 & 23977 \\
\hline & 40000 & 0.62 & 17900 & 54580 & 50898 & 23977 \\
\hline & 50000 & 0.78 & 5800 & 31599 & 29468 & 13817 \\
\hline \multirow{3}{*}{$517-647(\mathrm{~L}-\mathrm{H})$} & 30000 & 0.21 & 34800 & 29388 & 33160 & 37195 \\
\hline & 60000 & 0.42 & 26900 & 21576 & 24346 & 37036 \\
\hline & 80000 & 0.57 & 30600 & 15996 & 18049 & 36119 \\
\hline \multirow{6}{*}{$517-595(\mathrm{~L}-\mathrm{H})$} & 30000 & 0.21 & 63800 & 50928 & 54613 & 63996 \\
\hline & 30000 & 0.21 & 51600 & 50928 & 54613 & 63996 \\
\hline & 45000 & 0.31 & 56600 & 44482 & 47700 & 63005 \\
\hline & 60000 & 0.42 & 44700 & 37390 & 40096 & 60614 \\
\hline & 75000 & 0.52 & 46000 & 30944 & 33183 & 56455 \\
\hline & 90000 & 0.62 & 24800 & 24497 & 26270 & 49533 \\
\hline
\end{tabular}

Then, considering the average stress and the load interaction, the load interaction factor is expressed as

$$
\alpha_{i}=\frac{g\left(\sigma_{i}\right)}{g\left(\sigma_{i+1}\right)}=\left(\frac{\sigma_{\mathrm{a}, i}^{\gamma} \sigma_{\max , i}^{1-\gamma}}{\sigma_{\mathrm{a}, i+1}^{\gamma} \sigma_{\max , i+1}^{1-\gamma}}\right)^{\delta_{0}} .
$$

By substituting $\Delta X(n)$ for $n / N_{\mathrm{f}}$ in Equation (7), the damage model based on the ecological quality dissipation of the materials is given by

$$
D=\left(\frac{X(0)-X(n)}{X(0)-X\left(N_{\mathrm{f}}\right)}\right)^{g(\sigma)}=\left(\frac{1-e^{\left(e^{n / N_{\mathrm{f}}}-1\right)}}{1-e^{(e-1)}}\right)^{g(\sigma)}
$$

In two-level loading, according to the principle of equivalent damage, the damage caused by $n_{1}$ cycles under the firststage loading $\left(\sigma_{1}\right)$ is equal to that caused by $n_{2}^{\prime}$ cycles under 


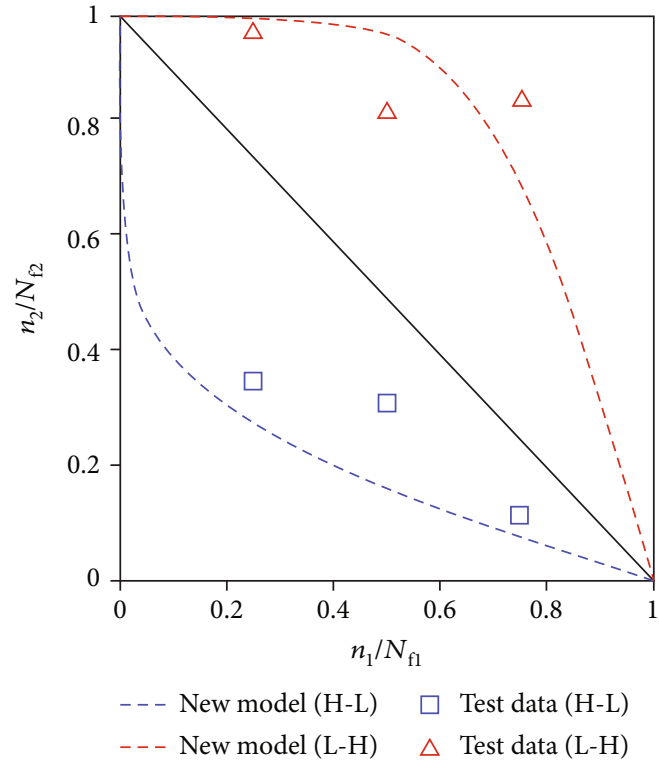

(a) $485-400 \mathrm{MPa}$

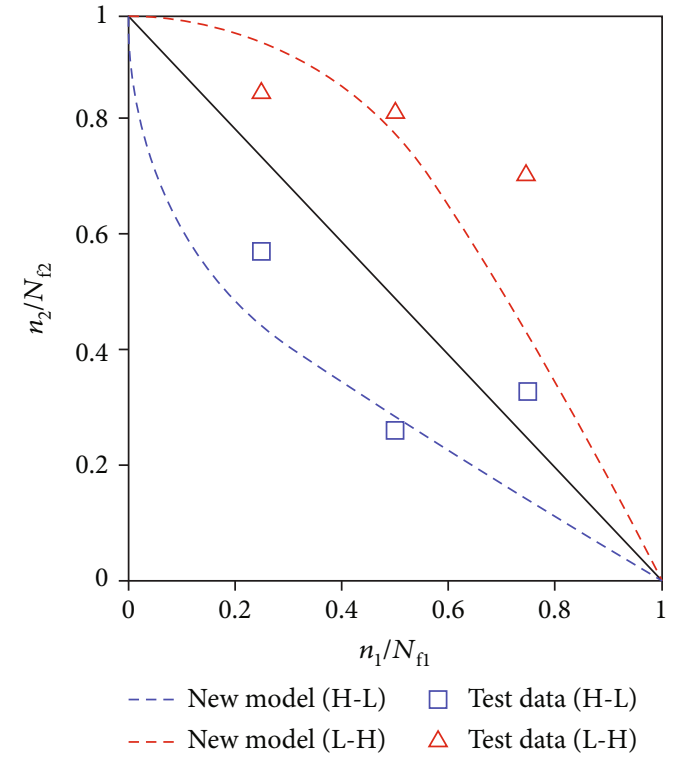

(b) $465-420 \mathrm{MPa}$

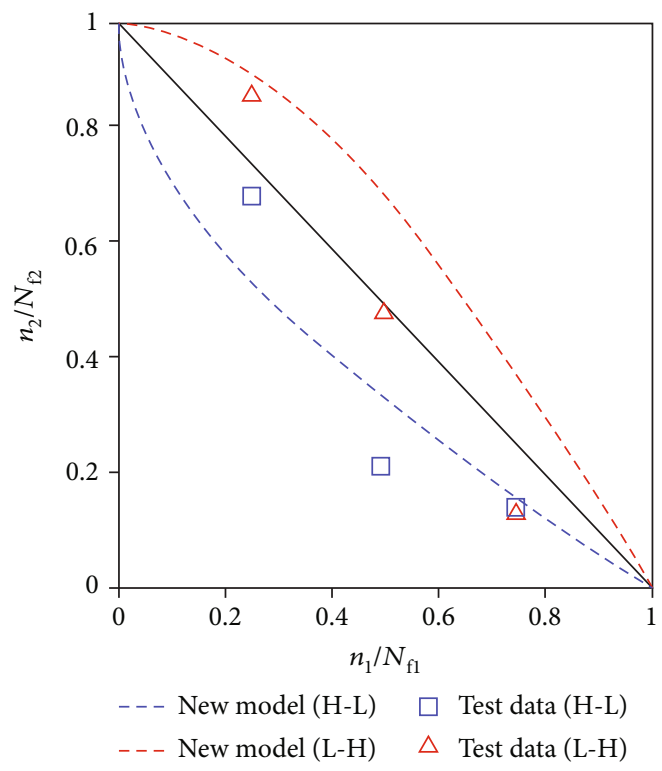

(c) $450-420 \mathrm{MPa}$

FIGURE 6: Relationships between cycling ratios of the 30NiCrMoV12 alloy steel under two-level cyclic loading.

the second-stage loading $\left(\sigma_{2}\right)$, i.e.:

$$
\left(\frac{\left.1-e^{\left(e^{n_{1} / N_{\mathrm{f} 1}}-1\right.}\right)}{1-e^{(e-1)}}\right)^{g\left(\sigma_{1}\right)}=\left(\frac{1-e^{\left(e^{n_{2}{ }^{\prime} / N_{\mathrm{f} 2}-1}\right)}}{1-e^{(e-1)}}\right)^{g\left(\sigma_{2}\right)},
$$

where $N_{\mathrm{f} 1}$ and $N_{\mathrm{f} 2}$ are the fatigue lives corresponding to $\sigma_{1}$ and $\sigma_{2}$, respectively.

According to Equation (13), we can obtain

$$
\frac{n_{2}{ }^{\prime}}{N_{\mathrm{f} 2}}=\ln \left\{1+\ln \left[1-\left(\frac{1-e^{\left(e^{n_{1} / N_{\mathrm{f} 1}}-1\right)}}{1-e^{(e-1)}}\right)^{\alpha_{1}}\left(1-e^{(e-1)}\right)\right]\right\} .
$$

Then, the remaining life fraction obtained at the secondstage load is

$$
\begin{aligned}
\frac{n_{2, \mathrm{res}}}{N_{\mathrm{f} 2}} & =1-\frac{n_{2}{ }^{\prime}}{N_{\mathrm{f} 2}} \\
& =1-\ln \left\{1+\ln \left[1-\left(\frac{1-e^{\left(e^{n_{1} / N_{\mathrm{f} 1}-1}\right)}}{1-e^{(e-1)}}\right)^{\alpha_{1}}\left(1-e^{(e-1)}\right)\right]\right\},
\end{aligned}
$$

where $n_{2, \text { res }}$ is the number of cycles up to fatigue failure under the second-stage load after $n_{1}$ cycles under the first-stage load. 


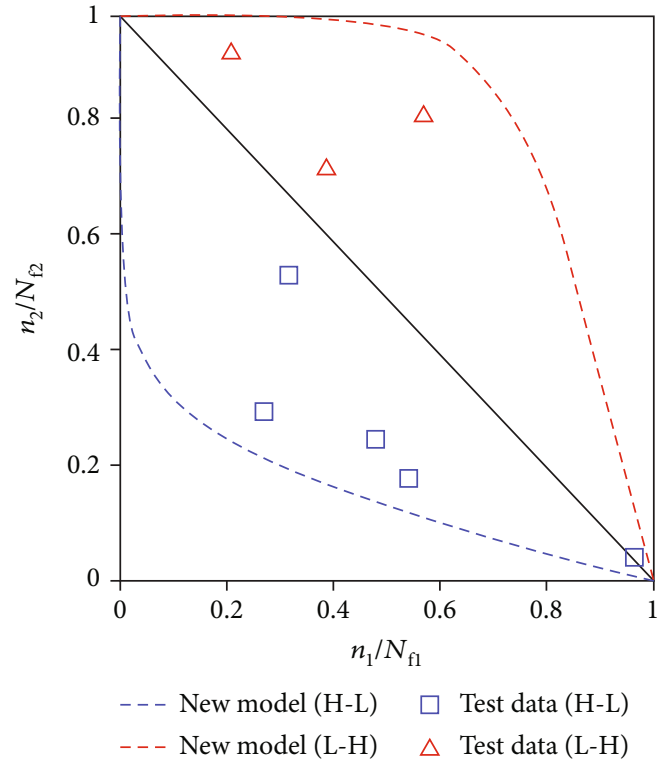

(a) $647-517 \mathrm{MPa}$

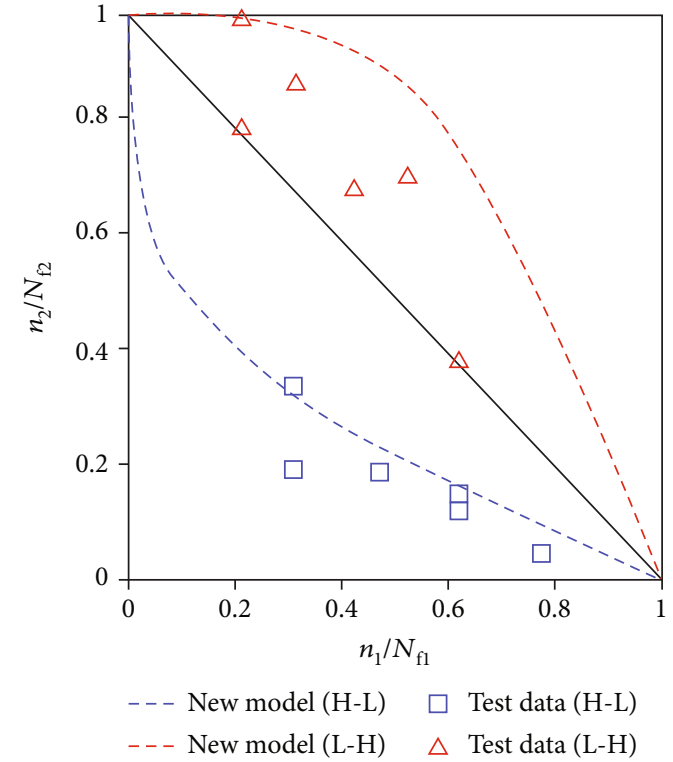

(b) $595-517 \mathrm{MPa}$

FIGURE 7: Relations between cycling ratios of the Ti-6Al-4V titanium alloy under two-level cyclic loading.

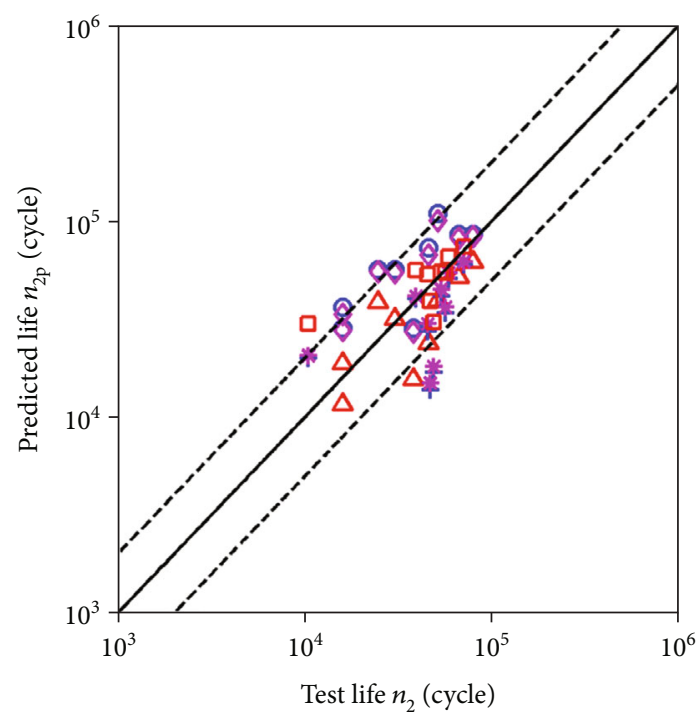

$$
\begin{array}{lll}
\bigcirc \text { Miner model (H-L) } & * \quad \text { Kwofie model (L-H) } \\
\diamond \text { Kwofie model (H-L) } & \square \quad \text { New model (L-H) } \\
\triangle \text { New model (H-L) } & -\quad n_{2}=n_{2 \mathrm{P}} \\
+ \text { Miner model (L-H) } & --- & \text { Life factor }=2
\end{array}
$$

FIGURE 8: Comparison of theoretically predicted and experimentally obtained remaining lives of the $30 \mathrm{NiCrMoV} 12$ alloy steel.

In three-level loading, according to the principle of equivalent damage, the remaining life fraction obtained at the third-stage load is

$\frac{n_{3, \text { res }}}{N_{\mathrm{f} 3}}=1-\ln \left\{1+\ln \left[1-\left(\frac{1-e^{\left(e^{\left(\left(n_{2} / N_{\mathrm{f} 2}\right)+1-\left(n_{2}, \text { res } / N_{\mathrm{f} 2}\right)\right)}-1\right)}}{1-e^{(e-1)}}\right)^{\alpha_{2}}\left(1-e^{(e-1)}\right)\right]\right\}$.

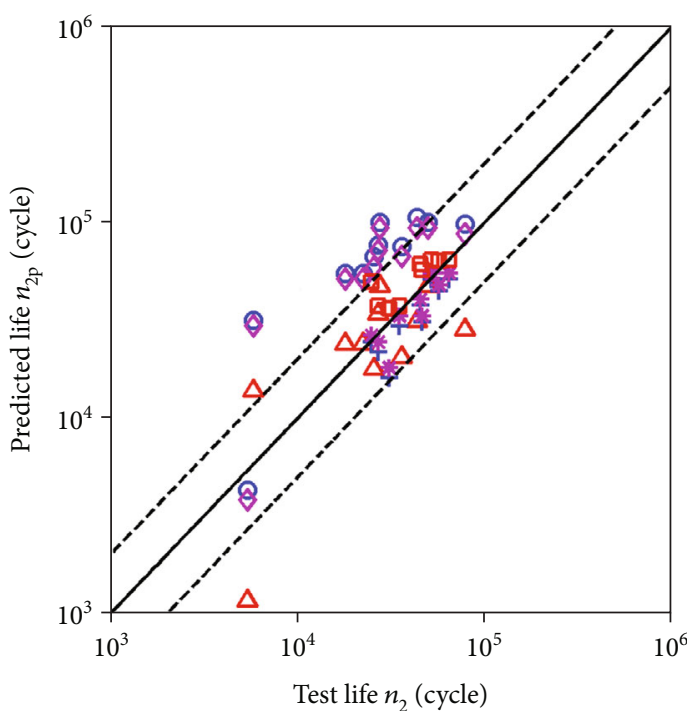

$$
\begin{array}{lll}
\bigcirc \text { Miner model (H-L) } & * & \text { Kwofie model (L-H) } \\
\diamond \text { Kwofie model (H-L) } & \square & \text { New model (L-H) } \\
\triangle \text { New model (H-L) } & -\quad & n_{2}=n_{2 \mathrm{P}} \\
+ \text { Miner model (L-H) } & --- & \text { Life factor }=2
\end{array}
$$

FIGURE 9: Comparison of theoretically predicted and experimentally obtained remaining lives of the Ti-6Al-4V titanium alloy.

By logical extension, the remaining life fraction at the $i^{\text {th }}$ stage load $(i>3)$ is

$\frac{n_{i \text { res }}}{N_{\mathrm{fi}}}=1-\ln \left\{1+\ln \left[1-\left(\frac{1-e^{\left(e^{\left(\left(n_{i-1} / N_{\mathrm{fi}-1}\right)+1-\left(n_{i-1, \text { res }} / N_{f i-1}\right)\right)}-1\right)}}{1-e^{(e-1)}}\right)^{\alpha_{i-1}}\left(1-e^{(e-1)}\right)\right]\right\}$. 


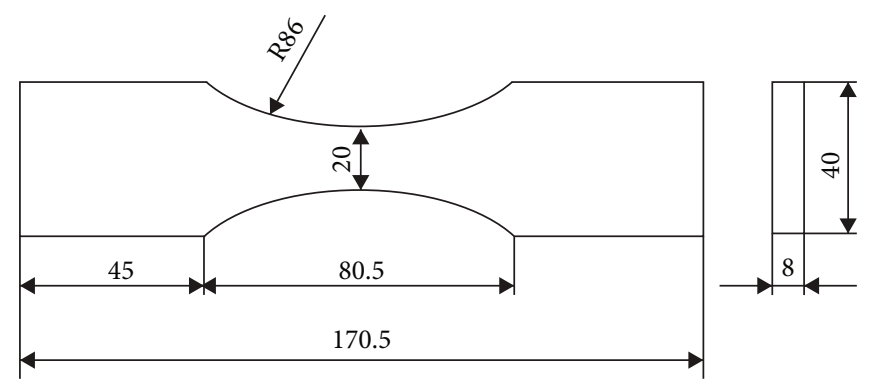

Figure 10: Geometry of 6082-T6 aluminium alloy specimens (dimensions in $\mathrm{mm}$ ).

TABLe 3: Experimentally obtained and corresponding theoretical remaining life values predicted by the Miner, Kwofie, and proposed new model for the 6082-T6 aluminium alloy under multilevel cyclic loading.

\begin{tabular}{|c|c|c|c|c|c|c|c|c|c|c|c|}
\hline \multirow{2}{*}{$\begin{array}{l}\text { Load sequence } \\
\sigma_{\max }(\mathrm{MPa})\end{array}$} & \multicolumn{5}{|c|}{ Test data } & \multicolumn{2}{|c|}{ Miner model } & \multicolumn{2}{|c|}{ Kwofie model } & \multicolumn{2}{|c|}{ New model } \\
\hline & $\begin{array}{c}n_{1} \\
\text { (cycle) }\end{array}$ & $\begin{array}{c}n_{2} \\
\text { (cycle) }\end{array}$ & $\begin{array}{c}n_{3} \\
\text { (cycle) }\end{array}$ & $\begin{array}{c}n_{4} \\
\text { (cycle) }\end{array}$ & $\begin{array}{c}n_{5} \\
\text { (cycle) }\end{array}$ & $\begin{array}{l}n_{\text {last,p }} \\
\text { (cycle) }\end{array}$ & $\begin{array}{c}\text { Error } \\
(\%)\end{array}$ & $\begin{array}{l}n_{\text {last,p }} \\
\text { (cycle) }\end{array}$ & $\begin{array}{c}\text { Error } \\
(\%)\end{array}$ & $\begin{array}{l}n_{\text {last, }} \\
\text { (cycle) }\end{array}$ & $\begin{array}{c}\text { Error } \\
(\%)\end{array}$ \\
\hline $260-275-290-305$ & 210000 & 110500 & 60000 & 54000 & - & 33750 & -37.5 & 44387 & -17.8 & 94537 & 75.1 \\
\hline $280-305-260-240$ & 19427 & 10950 & 26258 & 43400 & - & 136050 & 213.5 & 124351 & 186.5 & 32991 & -24.0 \\
\hline $\begin{array}{l}260-275-290-305- \\
260\end{array}$ & 210000 & 110500 & 60000 & 33750 & 116750 & 0 & -100.0 & 57314 & -50.9 & 149580 & 28.1 \\
\hline
\end{tabular}

The flowchart for illustrating the procedure of life prediction using the proposed model is shown in Figure 3.

\section{Results and Discussion}

The test data were obtained from References [11, 31-33] for the $30 \mathrm{NiCrMoV} 12$ alloy steel and Ti-6Al-4V titanium alloy under two-level cyclic loading and the 6082-T6 aluminium alloy under multilevel cyclic loading and were used to verify the applicability and prediction accuracy of the proposed new model. In addition, the predictions obtained using the proposed new model were compared with those obtained using the Miner model and Kwofie model.

3.1. Two-Level Cyclic Loading. Fatigue tests [11] were carried out on the hardened and tempered 30NiCrMoV12 alloy steel under high-low and low-high two-level loading. The geometry of specimens is shown in Figure 4. The mechanical properties of the alloy steel are the ultimate strength $\sigma_{\mathrm{u}}=1035 \mathrm{MPa}$, the yield strength $\sigma_{\mathrm{y}}=755 \mathrm{MPa}$, and the fatigue limit $\sigma_{\mathrm{f}}=391 \mathrm{MPa}$. The stress ratio $R$ is -1 . The test data [11] and corresponding theoretical remaining life values predicted by the Miner, Kwofie, and proposed new model are tabulated in Table 1.

Fatigue tests [31] were carried out on the Ti-6Al-4V titanium alloy under the two-level (high-low and low-high) loading by using an electrodynamic vibration system. The geometry of specimens is shown in Figure 5. The mechanical properties of the titanium alloy are the ultimate strength $\sigma_{\mathrm{u}}=1005 \mathrm{MPa}$, the yield strength $\sigma_{\mathrm{y}}=975 \mathrm{MPa}$, and the Young modulus $E=107 \mathrm{GPa}$. The stress ratio $R$ is -1 . The experimentally obtained data [31] and corresponding theoretical remaining life values predicted by the Miner, Kwofie, and proposed new model are tabulated in Table 2.
The relations between the cycling ratios of the $30 \mathrm{NiCr}-$ MoV12 alloy steel and Ti-6Al-4V titanium alloy under twolevel cyclic loading are shown in Figures 6 and 7, respectively. According Reference [15], the load sequence effect is the change in fatigue life due to a reordering of the load spectrum. Figures 6 and 7 show the effect of load sequence on damage accumulation. Under low-high loading, lowamplitude cyclic loading strengthened the fatigue properties of the materials. Afterward, when high-amplitude cyclic loading was applied, the accumulated fatigue damage did not deteriorate significantly. The fatigue lives predicted under low-high loading were longer than those predicted under constant-amplitude loading, and the sum of the damage was greater than 1. Under high-low loading, the materials were damaged, and the damage began to accumulate under high-amplitude cyclic loading. Afterward, when the lowamplitude cyclic loading was applied, the accumulated fatigue damage deteriorated further. The fatigue lives predicted under high-low loading were shorter than those predicted under constant-amplitude loading, and the sum of the damage was less than 1 . The proposed nonlinear fatigue damage accumulation model described more accurately the damage accumulated under variable-amplitude cyclic loading. The test data are in good agreement with the values predicted by the proposed new model. The greater the difference between the maximum values of the two loading stress levels, the more obvious the concavity and convexity of the curve corresponding to the proposed new model. This indicates that the greater the change in the rate of damage accumulation under variable-amplitude loading, the greater the impact of the load sequence on the fatigue life. Under high-low loading, when $n_{1} / N_{\mathrm{f} 1}$ is small, the greater the difference between the two loading levels, the greater the rate of change for $n_{2} /$ $N_{\mathrm{f} 2}$. When $n_{1} / N_{\mathrm{f} 1}$ is large, the greater the difference between 


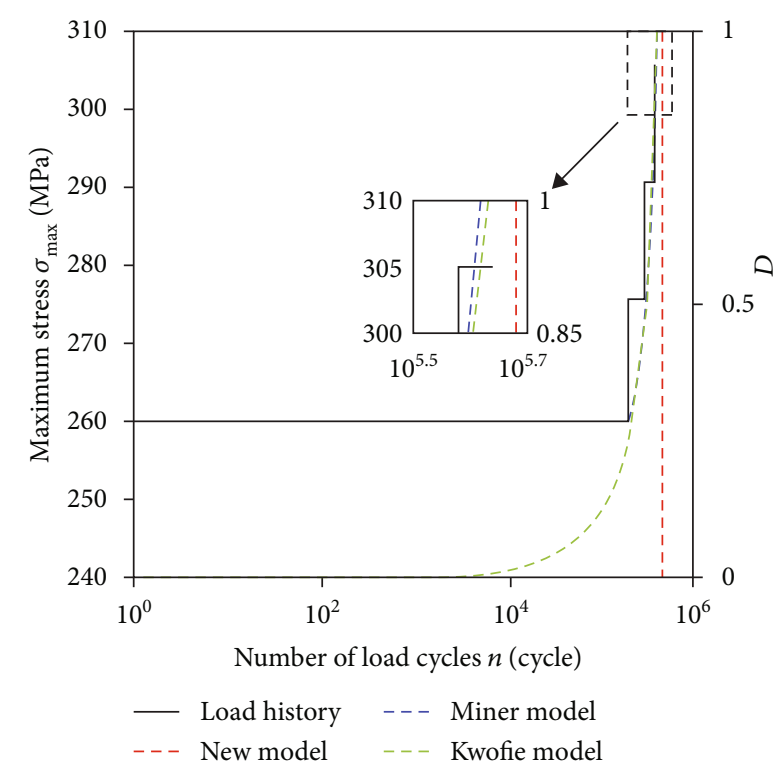

Figure 11: Comparison of experimentally obtained and corresponding theoretical remaining life values predicted by the Miner, Kwofie, and proposed new model for 6082-T6 aluminium alloy under four-level cyclic loading in the range 260-275-290$305 \mathrm{MPa}$.

the two loading levels, the smaller the rate of change for $n_{2} /$ $N_{\mathrm{f} 2}$. Under low-high loading, when $n_{1} / N_{\mathrm{f} 1}$ is small, the greater the difference between the two loading levels, the smaller the rate of change for $n_{2} / N_{\mathrm{f} 2}$. When $n_{1} / N_{\mathrm{f} 1}$ is large, the greater the difference between the two loading levels, the greater the rate of change for $n_{2} / N_{\mathrm{f} 2}$.

To further analyse the prediction accuracy of the proposed new model, the experimentally obtained and theoretically predicted remaining life values of the $30 \mathrm{NiCrMoV} 12$ alloy steel and $\mathrm{Ti}-6 \mathrm{Al}-4 \mathrm{~V}$ titanium alloy were compared, as shown in Figures 8 and 9.

Figure 8 clearly shows that for the $30 \mathrm{NiCrMoV} 12$ alloy steel, $72.2,77.8$, and $88.9 \%$ of the remaining life values predicted by the Miner, Kwofie, and proposed new model fall within scatter bands of 2 , respectively. Only two remaining life values predicted by the proposed new model are not within the scatter band of 2 . Figure 9 clearly shows that for the Ti-6Al-4V titanium alloy, 55.0, 65.0, and $85.0 \%$ of the remaining life values predicted by the Miner, Kwofie, and proposed new model fall within scatter bands of 2 , respectively. The remaining life values predicted by the Miner and Kwofie model are more widely distributed than those predicted by the proposed new model. Therefore, the proposed new model gives more accurate predictions and shows wider applicability.

3.2. Multilevel Cyclic Loading. Fatigue tests $[32,33]$ were carried out on the 6082-T6 aluminium alloy under multilevel cyclic loading. The geometry of specimens is shown in Figure 10. The mechanical properties of the aluminium alloy are the ultimate strength $\sigma_{\mathrm{u}}=370 \mathrm{MPa}$, the yield strength $\sigma_{\mathrm{y}}=347 \mathrm{MPa}$, and the Young modulus $E=73 \mathrm{GPa}$. The stress ratio $R$ is 0 . The experimentally obtained data [32,

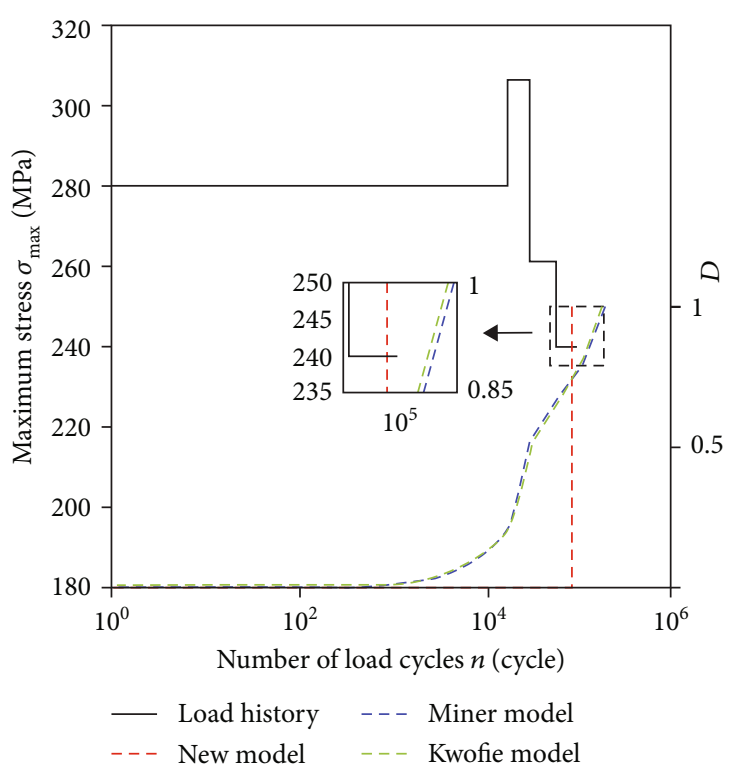

FIGURE 12: Comparison of experimentally obtained and corresponding theoretical remaining life values predicted by the Miner, Kwofie, and proposed new model for 6082-T6 aluminium alloy under four-level cyclic loading in the range 280-305-260$240 \mathrm{MPa}$.

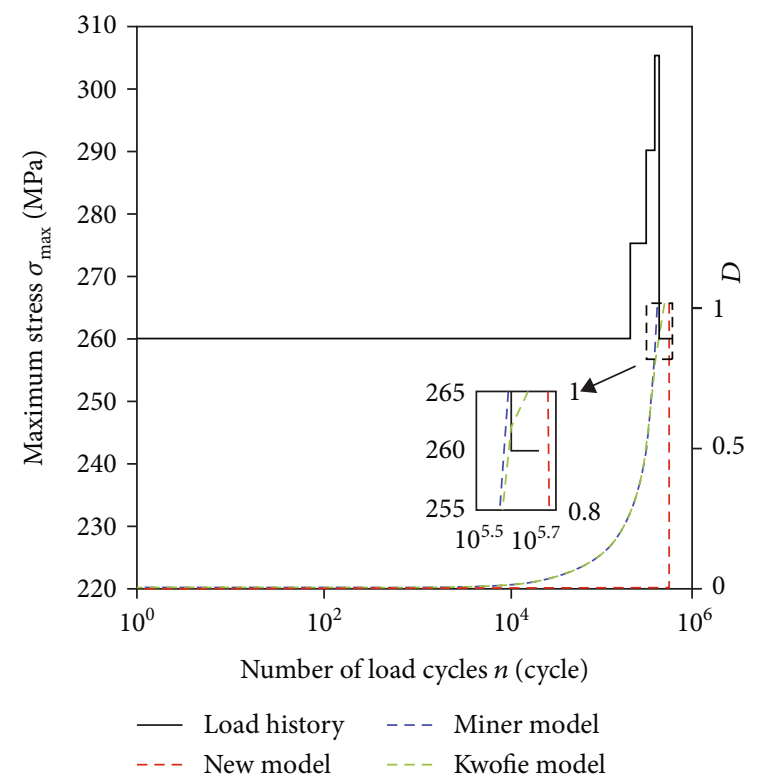

FIGURE 13: Comparison of experimentally obtained and corresponding theoretical remaining life values predicted by the Miner, Kwofie, and proposed new model for 6082-T6 aluminium alloy under five-level cyclic loading in the range 260-275-290305-260 MPa.

33] and corresponding theoretical remaining life values predicted by the Miner, Kwofie, and proposed new model are tabulated in Table 3 , where $n_{\text {last,p }}$ represents the remaining life values predicted by the theoretical models under the last stage of cyclic loading. All of the remaining life values predicted by the proposed new model fall within a scatter band of 2 and are more accurate than those predicted by the Miner 
model and Kwofie model. Because the Miner model does not consider the load sequence, the remaining life values predicted by it show a high degree of error. Even in some multilevel loadings, it is impossible to accurately predict the remaining fatigue life under the last stage of cyclic loading.

The load histories of the 6082-T6 aluminium alloy under multilevel cyclic loading and the corresponding accumulated fatigue damage are depicted in Figures 11-13, which clearly show the obvious deviation between the accumulated fatigue damage experimentally obtained and those theoretically predicted by the Miner model and Kwofie model. In multilevel cyclic loading, the changes in the damage accumulation rates predicted by the Miner model are discontinuous, especially under alternating high and low loadings. We believe that in the proposed new model, the damage accumulates very slowly in the initial stage of fatigue. At the end of fatigue, the damage accumulates fast, and the remaining life values predicted by the proposed new model are closer to the experimentally obtained ones. Therefore, the proposed new model is more suitable for studying the accumulative fatigue damage of engineering materials under multilevel cyclic loading, and the predictions obtained by the proposed new model are more accurate than those obtained by the Miner model and Kwofie model.

\section{Conclusions}

In this paper, a material performance degradation-based nonlinear fatigue damage accumulation model is proposed by introducing the concept of the ecology quality dissipation of materials. Test data obtained for three materials under multilevel cyclic loading are used for model validation and comparison. The conclusions are drawn as follows:

(1) The degradation of material performance with the increasing number of load cycles is analogous to the decomposition of litter over time. Through this analogy, a nonlinear fatigue damage accumulation model based on ecological quality dissipation of materials is proposed. The proposed model considers the influence of load interaction and sequence

(2) By using test data for the 30NiCrMoV12 alloy steel and Ti-6Al-4V titanium alloy under two-level cyclic loading and the 6082-T6 aluminium alloy under multilevel cyclic loading, the model validation and comparison are conducted. The results show that the fatigue lives predicted by the proposed new model are highly accurate. The proposed model provides a theoretical basis for damage analysis and life prediction of aircraft structures

\section{Data Availability}

Test data were obtained from References [11, 31-33] for the $30 \mathrm{NiCrMoV} 12$ alloy steel and Ti-6Al-4V titanium alloy under two-level cyclic loading and the 6082-T6 aluminium alloy under multilevel cyclic loading and were used to verify the applicability and prediction accuracy of the proposed new model.

\section{Conflicts of Interest}

The authors declare that there is no conflict of interest regarding the publication of this paper.

\section{References}

[1] M. S. Cheung and W. C. Li, "Probabilistic fatigue and fracture analyses of steel bridges," Structural Safety, vol. 25, no. 3, pp. 245-262, 2003.

[2] D. Liao, S. P. Zhu, B. Keshtegar, G. Qian, and Q. Wang, "Probabilistic framework for fatigue life assessment of notched components under size effects," International Journal of Mechanical Sciences, vol. 181, article 105685, 2020.

[3] W. X. Yao, Fatigue Life Estimation of Structures, Science Press, China, 2019.

[4] M. A. Miner, "Cumulative damage in fatigue," Journal of Applied Mechanics, vol. 12, no. 3, pp. 159-164, 1945.

[5] T. H. Topper, B. I. Sandor, and J. Morrow, "Cumulative fatigue damage under cyclic strain control," Journal of Materials, vol. 4, no. 1, 199 pages, 1969.

[6] L. Xie, W. Lv, and Z. Shi, "Experiment study on fatigue damage under two level loading," Journal of Mechanical Strength, vol. 16, no. 3, pp. 52-54, 1994.

[7] D. G. Shang and W. X. Yao, "A nonlinear damage cumulative model for uniaxial fatigue," International Journal of Fatigue, vol. 21, no. 2, pp. 187-194, 1999.

[8] H. T. Corten and T. J. Dolan, "Cumulative fatigue damage. Proceedings of the International Conference on the Fatigue of Metals of Institution of Mechanical Engineers, ASME, London, 1956.

[9] Q. Liu, Y. Gao, Y. Li, and Q. Xue, "Fatigue life prediction based on a novel improved version of the Corten-Dolan model considering load interaction effect," Engineering Structures, vol. 221, article 111036, 2020.

[10] J. L. Chaboche and P. M. Lesne, "A non-linear continuous fatigue damage model," Fatigue \& Fracture of Engineering Materials \& Structures, vol. 11, no. 1, pp. 1-17, 1988.

[11] V. Dattoma, S. Giancane, R. Nobile, and F. W. Panella, "Fatigue life prediction under variable loading based on a new non-linear continuum damage mechanics model," International Journal of Fatigue, vol. 28, no. 2, pp. 89-95, 2006.

[12] T. Gao, J. Jing, C. Chen, J. Cong, J. Li, and S. Cao, “A practical nonlinear damage accumulation method to predict the life and crack propagation of blade subjected to multilevel cyclic fatigue loads," Journal of Strain Analysis for Engineering Design, vol. 55, no. 3-4, pp. 86-98, 2020.

[13] S. Kwofie and N. Rahbar, "A fatigue driving stress approach to damage and life prediction under variable amplitude loading," International Journal of Damage Mechanics, vol. 22, no. 3, pp. 393-404, 2012.

[14] Z. Peng, H. Z. Huang, H. K. Wang, S. P. Zhu, and Z. Lv, “A new approach to the investigation of load interaction effects and its application in residual fatigue life prediction," International Journal of Damage Mechanics, vol. 25, no. 5, pp. 672-690, 2016.

[15] S. P. Zhu, Y. Z. Hao, J. Correia, G. Lesiuk, and A. Jesus, "Nonlinear fatigue damage accumulation and life prediction of 
metals: a comparative study," Fatigue \& Fracture of Engineering Materials \& Structures, vol. 42, no. 6, pp. 1271-1282, 2019.

[16] F. L. Xia, S. P. Zhu, D. Liao, R. Dantas, J. Correia, and A. Jesus, "Isodamage curve-based fatigue damage accumulation model considering the exhaustion of static toughness," Engineering Failure Analysis, vol. 115, article 104575, 2020.

[17] E. Böhm, M. Kurek, G. Junak, M. Cieśla, and T. Łagoda, "Accumulation of fatigue damage using memory of the material," Procedia Materials Science, vol. 3, pp. 2-7, 2014.

[18] H. Ebbinghaus, Memory: A Contribution to Experimental Psychology, Columbia University, Teachers College, New York, USA, 1913.

[19] Z. Peng, H. Z. Huang, J. Zhou, and Y. F. Li, "A new cumulative fatigue damage rule based on dynamic residual S-N curve and material memory concept," Metals, vol. 8, no. 6, p. 456, 2018.

[20] J. Zhou, H. Z. Huang, M. V. Barnhart, and G. Huang, “A novel non-linear cumulative fatigue damage model based on the degradation of material memory," International Journal of Damage Mechanics, vol. 29, no. 4, pp. 610-625, 2019.

[21] K. N. Smith, P. Watson, and T. H. Topper, "Stress-strain function for the fatigue of metals," Journal of Materials, vol. 5, no. 4, 778 pages, 1970.

[22] S. K. Koh and R. I. Stephens, "Mean stress effects on low cycle fatigue for a high strength steel," Fatigue \& Fracture of Engineering Materials \& Structures, vol. 14, no. 4, pp. 413-428, 1991.

[23] D. Ye, D. Wang, X. Tong, and L. Yao, “A new approach for studying fatigue damage," Journal of Experimental Mechanics, vol. 14, no. 1, pp. 80-88, 1999.

[24] L. Li, L. Xie, X. He, and G. Hao, "Strength degradation law of metallic material under fatigue loading," Journal of Mechanical Strength, vol. 32, no. 6, pp. 967-971, 2010.

[25] J. S. Olson, "Energy storage and the balance of producers and decomposers in ecological systems," Ecology, vol. 44, no. 2, pp. 322-331, 1963.

[26] P. Rovira and R. Rovira, "Fitting litter decomposition datasets to mathematical curves: towards a generalised exponential approach," Geoderma, vol. 155, no. 3-4, pp. 329-343, 2010.

[27] J. Zhou, Fatigue Life Prediction and Reliability Analysis of Aero-Engine Turbine Blades, University of Electronic Science Technology of China, Chengdu, China, 2019.

[28] K. Walker, "The effect of stress ratio during crack propagation and fatigue for 2024-T3 and 7075-T6 aluminum," in Effects on Environment and Complex Load History on Fatigue Life, M. Rosenfeld, Ed., ASTM International, PA, West Conshohocken, 1970.

[29] N. E. Dowling, C. A. Calhoun, and A. Arcari, "Mean stress effects in stress-life fatigue and the Walker equation," Fatigue \& Fracture of Engineering Materials \& Structures, vol. 32, no. 3, pp. 163-179, 2009.

[30] Z. Lv, Research on Low Cycle Fatigue Life Prediction Methodology of Aero-Engine Disc, University of Electronic Science Technology of China, Chengdu, China, 2016.

[31] S. Yang, Research on Crack Initiation and Propagation Life Prediction of Turbofan Engine High Pressure Compressor Blade, Tianjin University, Tianjin, China, 2015.
[32] G. Mesmacque, S. Garcia, A. Amrouche, and C. Rubiogonzalez, "Sequential law in multiaxial fatigue, a new damage indicator," International Journal of Fatigue, vol. 27, no. 4, pp. 461-467, 2005.

[33] A. Aid, A. Amrouche, B. B. Bouiadjra, M. Benguediab, and G. Mesmacque, "Fatigue life prediction under variable loading based on a new damage model," Materials \& Design, vol. 32, no. 1, pp. 183-191, 2011. 